\title{
Surface Cooling, Winds, and Eddies over the Continental Shelf
}

\author{
K. H. BRINK \\ Department of Physical Oceanography, Woods Hole Oceanographic Institution, Woods Hole, Massachusetts
}

(Manuscript received 24 August 2016, in final form 6 February 2017)

\begin{abstract}
Models show that surface cooling over a sloping continental shelf should give rise to baroclinic instability and thus tend toward gravitationally stable density stratification. Less is known about how alongshore winds affect this process, so the role of surface momentum input is treated here by means of a sequence of idealized, primitive equation numerical model calculations. The effects of cooling rate, wind amplitude and direction, bottom slope, bottom friction, and rotation rate are all considered. All model runs lead to instability and an eddy field. While instability is not strongly affected by upwelling-favorable alongshore winds, wind-driven downwelling substantially reduces eddy kinetic energy, largely because the downwelling circulation plays a similar role to baroclinic instability by flattening isotherms and so reducing available potential energy. Not surprisingly, cross-shelf winds appear to have little effect. Analysis of the model runs leads to quantitative relations for the wind effect on eddy kinetic energy for the equilibrium density stratification (which increases as the cooling rate increases) and for eddy length scale.
\end{abstract}

\section{Introduction}

Strong surface cooling generally leads to a deep surface mixed layer because cold, dense surface water creates a gravitationally unstable water column. When this layer reaches to the bottom over the continental shelf, shallower waters cool faster than deeper waters, and a cross-shelf temperature (density) gradient develops. It is well understood from models (e.g., Whitehead 1981; Chapman and Gawarkiewicz 1997; Pringle 2001; Spall 2013) that this gradient gives rise to baroclinic instabilities that, in turn, transport heat toward shallower water and eventually create gravitationally stable density stratification. When regionalscale alongshore advection is important, however, the importance of the cross-shelf eddy heat flux appears to be mitigated (Spall 2005). In many of these cases, interest was particularly focused on the cross-shelf eddy heat transport (e.g., Spall and Chapman 1998), and so some of the other interesting aspects of the problem, such as the actual eddy kinetic energy or the growth of density stratification despite cooling, did not receive as much explicit attention. Further, there is a complementary literature dealing with cooling in the Southern Ocean (e.g., Stewart and Thompson 2015) that tends to

\footnotetext{
Corresponding authore-mail: kbrink@whoi.edu
}

deal more with transports on larger scales in deeper offshore water.

Cooling over shelves is expected to be a common process at mid- and higher latitudes. However, in these wintertime conditions, surface wind forcing is also expected to be an important driver. While this has been included, on the large scales, in the Antarctic models (e.g., Stewart and Thompson 2015), it has received a good deal less attention in the coastal literature. One focused coastal study that does account for wind forcing in the presence of cooling is that of Whitehead (1981), where he briefly describes laboratory models that address this question.

What is the expected ocean response to winds in the presence of cooling? First, imagine a stagnant coastal ocean subject to cooling: isopycnals will initially be vertical over the shelf, with the densest water near the shore. This system is known to be baroclinically unstable (e.g., Pringle 2001). If upwelling-favorable alongshore winds are superimposed, there will be offshore transport near the surface, carrying denser water over lighter ambient waters. Likewise, deep wind-driven flow is onshore, carrying lighter water beneath dense water. The resulting gravitationally unstable configuration will then presumably lead to vertical mixing and a density field not much changed from the initial state. Thus, the pool of available potential energy (APE) is expected to be largely unchanged relative to the case with no winds. 
One might thus expect that upwelling-favorable alongshore winds would have little impact when it comes to baroclinic instability and the consequent eddy field development.

In contrast, if alongshore winds are downwelling favorable, near-surface flow carries warmer waters onshore, while deep offshore flow carries denser waters offshore. The net effect is to create a gravitationally stable density field where isopycnals tilt downward offshore. This configuration has less available potential energy than the initial state and so one would ultimately expect to have a less energetic eddy field. One might ask whether winds can be strong enough to inhibit eddy formation altogether.

It is important to note that these conjectured wind effects only account for the wind's influence on the available potential energy, hence on strictly baroclinic instability. The wind's potential influence in driving shear instabilities (related to either horizontal or vertical shear) has been ignored to this point. However, a substantial effect is possible because, for example, upwelling-favorable winds drive a positive alongshore flow, which, being surface intensified, enhances the alongshore vertical shear associated with the thermal wind.

Why should one care about the resulting eddy kinetic energy (EKE)? The shelf eddy field is interesting in its own right, as it appears to help govern flow properties such as current isotropy and correlation scales (e.g., Brink and Seo 2016). Further, the eddy kinetic energy and its characteristic scales are expected to affect strongly the eddy transports of heat and very likely of other interesting properties, such as nutrient concentrations.

The primary goal of the present study is to ask what effect winds have on the eddy field in a coastal ocean undergoing sustained cooling. The approach for dealing with this question is to exploit idealized numerical models that contain enough of the core physical processes to yield meaningful answers but be simple enough to interpret directly. Along the way, the focus is on eddy kinetic energy, but a range of subsidiary issues is also addressed, including eddy length scales and the establishment of stratification.

\section{Methodology}

\section{a. Model configuration}

All model runs use the Regional Ocean Modeling System (ROMS), a primitive equation, hydrostatic numerical modeling system that has a stretched terrain-following vertical coordinate (e.g., Haidvogel et al. 2000). The governing equations are

$$
\begin{aligned}
u_{t}+u u_{x}+v u_{y}+w u_{z}-f v & =-\rho_{0}^{-1} p_{x}+\left(D u_{z}\right)_{z} \\
v_{t}+u v_{x}+v v_{y}+w v_{z}+f u & =-\rho_{0}^{-1} p_{y}+\left(D v_{z}\right)_{z} \\
0 & =-p_{z}-g \rho \\
u_{x}+v_{y}+w_{z} & =0 \\
\rho_{t}+u \rho_{x}+v \rho_{y}+w \rho_{z} & =\left(B \rho_{z}\right)_{z}, \quad \text { and } \\
\rho & =\rho_{0}\left[1-\beta\left(T-T_{0}\right)\right],
\end{aligned}
$$

where $u, v$, and $w$ are the cross-shelf, along-shelf, and vertical velocity components, corresponding to the $x, y$, and $z$ directions. Subscripts with regard to independent variables represent partial differentiation. Time is $t$, the pressure is $p, T$ is temperature, $\rho$ is density, $f$ is the Coriolis parameter, $g$ is the acceleration due to gravity, and $\rho_{0}$ is a constant reference density. The term $T_{0}$ is a reference temperature $\left(14^{\circ} \mathrm{C}\right), \beta$ is the thermal expansion coefficient for water $\left(1.7 \times 10^{-4}{ }^{\circ} \mathrm{C}^{-1}\right)$, and $D$ and $B$ are the vertical turbulent viscosity and mixing coefficients, respectively. These vertical exchange coefficients are found using the Mellor-Yamada level-2.5 turbulence closure scheme (e.g., Wijesekera et al. 2003). There is no explicit lateral mixing or viscosity. Because the equation of state for seawater is nonlinear, in reality $\beta$ varies as the reference temperature changes. Thus, the relation of buoyancy flux to heat flux changes with temperature: if the following results are to be applied in a context with a lower initial temperature, caution must be used in estimating heat or buoyancy fluxes.

The bottom boundary condition takes the form

$$
D\left(u_{z}, v_{z}\right)=r(u, v),
$$

where $r$ is a constant linear resistance coefficient. In most runs, the surface alongshore wind stress has amplitude $\tau_{A}$ and is ramped on and off as follows:

$\tau^{y}=0$ for $t<t_{1}$

$\tau^{y}=0.5 \tau_{A}\left[1-\cos \left(\pi\left(t-t_{1}\right) / t_{R}\right)\right]$ for $t_{1}<t<\left(t_{1}+t_{R}\right)$,

$\tau^{y}=\tau_{A}$ for $\left(t_{1}+t_{R}\right)<t<t_{2}$

$\tau^{y}=0.5 \tau_{A}\left[1+\cos \left(\pi\left(t-t_{2}\right) / t_{R}\right)\right]$ for $t_{2}<t<\left(t_{2}+t_{R}\right)$,

and

$$
\tau^{y}=0 \text { for } t>\left(t_{2}+t_{R}\right)
$$

For all runs reported here, $t_{R}=1$ day, $t_{1}=5-20$ days, and $t_{2}=60$ days. Two additional runs were executed with uniform cross-shelf winds having the same temporal form as (3), and three runs were executed with a sinusoidal alongshore wind stress starting from zero with no ramp at $t=t_{1}$ and ending at $t=t_{2}$ (an integral number 
of periods later). At the surface, a spatially uniform heat flux $Q$ is applied at all times for all runs. This is always negative, corresponding to ocean cooling, and is usually $-300 \mathrm{~W} \mathrm{~m}^{-2}$, roughly following Pringle (2001). All runs are initiated from rest, although at time $t=0$, there is an $O\left(10^{-4}\right) \mathrm{m}$ random noise applied to the otherwise flat sea surface. Some runs are initialized with a constant stratification (typically $0.03^{\circ} \mathrm{m}^{-1}$ ), but this is found to have no substantial effect on the results (cf. runs 21-23 to runs 1-3 in Table 1). It should be emphasized, however, that this lack of sensitivity here reflects the rapid (a few days) removal of initial stratification by relatively strong surface cooling $\left(Q=-129\right.$ to $\left.-300 \mathrm{~W} \mathrm{~m}^{-2}\right)$.

The bottom topography (Fig. 1) consists of two linear segments, representing the shelf and slope, adjoining a somewhat deeper, flat bottom ocean. Specifically,

$$
\begin{aligned}
& h=h_{0}+\alpha_{1} x \text { for } x<x_{1}, \\
& h=h_{0}+\alpha_{1} x_{1}+\alpha_{2}\left(x-x_{1}\right) \text { for } x_{1}<x<x_{2},
\end{aligned}
$$

and

$h=h_{0}+\alpha_{1} x_{1}+\alpha_{2}\left(x_{2}-x_{1}\right) \equiv h_{M} \quad$ for $\quad x_{2}<x$

The topography is smoothed slightly to avoid sharp corners, and $h_{M}=h_{0}+195 \mathrm{~m}$. The changes in slope always occur at $x_{1}=30 \mathrm{~km}$ and $x_{2}=40 \mathrm{~km}$. These length scales were chosen as computationally convenient: comparison with results when the shelf is wider $\left(x_{1}=45 \mathrm{~km}\right)$ does not reveal any sensitivity (e.g., of eddy energy or length scales) inshore of $x=25 \mathrm{~km}$ to overall shelf width. Grid resolution is $0.15 \mathrm{~km}$ in the alongshore direction, and the grid is gradually stretched from $0.15-$ to $0.25-\mathrm{km}$ resolution in the cross-shelf direction, with finer resolution near the coast. The domain is cyclic in the alongshore direction (channel length being $90 \mathrm{~km}$ ), and there is a free-slip wall at $x=0$. The offshore boundary $(x=55 \mathrm{~km})$ nudges (20-day time scale) temperature toward a constant value (typically $14^{\circ}$, but decreasing this by up to $5^{\circ}$ makes no difference for length scales, and shelf EKE changes by only about $10 \%$ ). Free surface height obeys a radiation condition, and depth-dependent velocity obeys a nonormal gradient condition.

A sequence of 61 90-day model runs (Table 1) is executed. Aside from the three runs with sinusoidal time dependence for wind stress, most runs are carried out in triads: one run with $\tau_{A}=0$, one with $\tau_{A}>0$, and one with $\tau_{A}<0$ (having the same strength as the $\tau_{A}>0$ case). This approach makes it straightforward to assess the wind's effect directly. Parameters that are varied, singly or in combinations, include $f, h_{0}, \alpha_{1}, Q, r$, and $\tau_{A}$. The runs are summarized in Table 1 , where each triad is numbered, and the runs are grouped according to parameters that are varied. For example, triads 1-4 all involve variations of the wind amplitude $\tau_{A}$. In addition, five nontriad runs $(9,29,52,53$, and 56) were executed to explore parameter space in the absence of winds: each of these is listed as a "triad" containing only one run. This arrangement involves repeated appearances of some runs (like number 1 ) that represent the $\tau_{A}=0$ member of several triads. The three sinusoidal runs (triad 26) are identical, except that the forcing period varies (2-, 5-, and 10-day periods).

\section{b. Model diagnostics}

The statistics arising from model runs are computed based on an along-channel average $\{q\}$ and deviations from this average $q^{\prime}(x, y, z, t)$. For example, the eddy kinetic energy per unit mass is

$$
\operatorname{eke}(x, z, t)=\frac{1}{2}\left\{u^{\prime 2}+v^{\prime 2}\right\}
$$

For convenience, most results (e.g., Fig. 2) are expressed in terms of spatially averaged (over depth and crossshelf distance) quantities. For example, the averaged mean kinetic energy, eddy kinetic energy, and gravitational potential energy (all per unit mass) are

$$
\begin{aligned}
\operatorname{MKE}(t) & =\frac{1}{2 A} \int_{0}^{W} \int_{-h}^{0}\left(\{u\}^{2}+\{v\}^{2}\right) d z d x, \\
\operatorname{EKE}(t) & =\frac{1}{2 A} \int_{0}^{W} \int_{-h}^{0}\left\{u^{\prime 2}+v^{\prime 2}\right\} d z d x \\
& =\frac{1}{A} \int_{0}^{W} \int_{-h}^{0} \text { eke } d z d x, \text { and } \\
\operatorname{PE}(t) & =\frac{1}{\rho_{0} A} \int_{0}^{W} \int_{-h}^{0}\{g \rho z\} d z d x,
\end{aligned}
$$

where $W=25 \mathrm{~km}$ (a location on the shelf but well inshore of its edge; Fig. 1),

$$
A=W\left(h_{0}+\alpha_{1} W / 2\right) \equiv W H
$$

is the $(x, z)$ area covered by the integral, and $H$ is the average water depth in the area. Note that the form (5d) does not lend itself to defining an eddy potential energy. Experimentation with $W=15 \mathrm{~km}$, while it changed some quantities, did not lead to any substantial differences in any of the conclusions that follow.

Of particular interest are the averaged conversion rates (per unit mass) of potential to kinetic energy

$$
C_{\mathrm{PE} \rightarrow \mathrm{KE}}=-\frac{g}{\rho_{0} A} \int_{0}^{W} \int_{-h}^{0}\{w \rho\} d z d x
$$

and the conversion rate from mean kinetic energy to eddy kinetic energy 
TABLE 1. Summary of numerical model runs.

\begin{tabular}{|c|c|c|c|c|c|c|c|c|c|c|c|}
\hline Triad & Run & $f\left(\times 10^{4} \mathrm{~s}^{-1}\right)$ & $\alpha_{1}$ & $h_{0}(\mathrm{~m})$ & $r\left(\times 10^{4} \mathrm{~s}^{-1}\right)$ & $Q\left(\mathrm{~W} \mathrm{~m}^{-2}\right)$ & $\tau_{A}\left(\mathrm{~N} \mathrm{~m}^{-2}\right)$ & $t_{1}$ (days) & $\operatorname{EKE}\left(\times 100 \mathrm{~m}^{2} \mathrm{~s}^{-2}\right)$ & $N^{2}\left(\times 10^{5} \mathrm{~s}^{-2}\right)$ & $\lambda(\mathrm{km})$ \\
\hline \multirow[t]{3}{*}{1} & 1 & 1.0 & 0.0021 & 5 & 5 & -300 & 0 & - & 0.87 & 6.0 & 29 \\
\hline & 2 & 1.0 & 0.0021 & 5 & 5 & -300 & 0.05 & 20 & 0.90 & 4.4 & 28 \\
\hline & 3 & 1.0 & 0.0021 & 5 & 5 & -300 & -0.05 & 20 & 0.42 & 5.6 & 28 \\
\hline \multirow[t]{3}{*}{2} & 1 & 1.0 & 0.0021 & 5 & 5 & -300 & 0 & - & 0.87 & 6.0 & 29 \\
\hline & 27 & 1.0 & 0.0021 & 5 & 5 & -300 & 0.025 & 20 & 0.97 & 6.0 & 29 \\
\hline & 28 & 1.0 & 0.0021 & 5 & 5 & -300 & -0.025 & 20 & 0.56 & 7.0 & 26 \\
\hline \multirow[t]{3}{*}{3} & 1 & 1.0 & 0.0021 & 5 & 5 & -300 & 0 & - & 0.87 & 6.0 & 29 \\
\hline & 5 & 1.0 & 0.0021 & 5 & 5 & -300 & 0.10 & 20 & 0.87 & 2.3 & 27 \\
\hline & 4 & 1.0 & 0.0021 & 5 & 5 & -300 & -0.10 & 20 & 0.28 & 3.6 & 29 \\
\hline \multirow[t]{3}{*}{4} & 1 & 1.0 & 0.0021 & 5 & 5 & -300 & 0 & - & 0.87 & 6.0 & 29 \\
\hline & 55 & 1.0 & 0.0021 & 5 & 5 & -300 & 0.25 & 20 & 0.90 & 1.2 & 22 \\
\hline & 54 & 1.0 & 0.0021 & 5 & 5 & -300 & -0.25 & 20 & 0.24 & 2.2 & 20. \\
\hline \multirow[t]{3}{*}{5} & 1 & 1.0 & 0.0021 & 5 & 5 & -300 & 0 & - & 0.87 & 6.0 & 29 \\
\hline & 20 & 1.0 & 0.0021 & 5 & 5 & -300 & 0.05 & 5 & 0.86 & 4.7 & 23 \\
\hline & 19 & 1.0 & 0.0021 & 5 & 5 & -300 & -0.05 & 5 & 0.52 & 5.4 & 29 \\
\hline 6 & 9 & 1.0 & 0.0021 & 5 & 0 & -300 & 0 & - & 4.10 & 7.3 & 38 \\
\hline \multirow[t]{3}{*}{7} & 6 & 1.0 & 0.0021 & 5 & 1 & -300 & 0 & - & 1.76 & 5.7 & 32 \\
\hline & 8 & 1.0 & 0.0021 & 5 & 1 & -300 & 0.05 & 20 & 1.80 & 3.2 & 36 \\
\hline & 7 & 1.0 & 0.0021 & 5 & 1 & -300 & -0.05 & 20 & 0.67 & 5.4 & 30. \\
\hline \multirow[t]{3}{*}{8} & 34 & 0.5 & 0.0021 & 5 & 10 & -300 & 0 & - & 0.70 & 4.6 & 35 \\
\hline & 32 & 0.5 & 0.0021 & 5 & 10 & -300 & 0.05 & 20 & 0.63 & 2.8 & 34 \\
\hline & 33 & 0.5 & 0.0021 & 5 & 10 & -300 & -0.05 & 20 & 0.46 & 3.0 & 33 \\
\hline 9 & 29 & 1.0 & 0.0021 & 5 & 20 & -300 & 0 & - & 0.64 & 8.2 & 23 \\
\hline 10 & 53 & 1.0 & 0.0021 & 5 & 50 & -300 & 0 & - & 0.61 & 8.0 & 26 \\
\hline \multirow[t]{3}{*}{11} & 13 & 0.5 & 0.0021 & 5 & 5 & -300 & 0 & - & 0.93 & 3.5 & 33 \\
\hline & 14 & 0.5 & 0.0021 & 5 & 5 & -300 & 0.05 & 20 & 0.86 & 1.9 & 33 \\
\hline & 15 & 0.5 & 0.0021 & 5 & 5 & -300 & -0.05 & 20 & 0.50 & 2.7 & 38 \\
\hline \multirow[t]{3}{*}{12} & 38 & 2.0 & 0.0021 & 5 & 5 & -300 & 0 & - & 1.10 & 15.5 & 16 \\
\hline & 40 & 2.0 & 0.0021 & 5 & 5 & -300 & 0.05 & 20 & 1.29 & 10.6 & 17 \\
\hline & 39 & 2.0 & 0.0021 & 5 & 5 & -300 & -0.05 & 20 & 0.46 & 10.6 & 15 \\
\hline 13 & 52 & 1.0 & 0.0021 & 5 & 5 & -43 & 0 & - & 0.23 & 3.6 & 15 \\
\hline \multirow[t]{3}{*}{14} & 10 & 1.0 & 0.0021 & 5 & 5 & -129 & 0 & - & 0.30 & 3.9 & 17 \\
\hline & 12 & 1.0 & 0.0021 & 5 & 5 & -129 & 0.05 & 20 & 0.16 & 0.6 & 12 \\
\hline & 11 & 1.0 & 0.0021 & 5 & 5 & -129 & -0.05 & 20 & 0.06 & 2.3 & 27 \\
\hline 15 & 56 & 1.0 & 0.0012 & 5 & 5 & -300 & 0 & - & 0.92 & 21.3 & 35 \\
\hline \multirow[t]{3}{*}{16} & 16 & 1.0 & 0.0045 & 5 & 5 & -300 & 0 & - & 0.79 & 2.2 & 22 \\
\hline & 18 & 1.0 & 0.0045 & 5 & 5 & -300 & 0.05 & 20 & 0.83 & 1.5 & 22 \\
\hline & 17 & 1.0 & 0.0045 & 5 & 5 & -300 & -0.05 & 20 & 0.40 & 1.7 & 24 \\
\hline \multirow[t]{3}{*}{17} & 24 & 1.0 & 0.0021 & 55 & 5 & -300 & 0 & - & 0.20 & 0.08 & 30. \\
\hline & 25 & 1.0 & 0.0021 & 55 & 5 & -300 & 0.05 & 20 & 0.16 & 1.0 & 17 \\
\hline & 26 & 1.0 & 0.0021 & 55 & 5 & -300 & -0.05 & 20 & 0.12 & 0.1 & 20. \\
\hline \multirow[t]{3}{*}{18} & 24 & 1.0 & 0.0021 & 55 & 5 & -300 & 0 & - & 0.20 & 0.08 & 30. \\
\hline & 31 & 1.0 & 0.0021 & 55 & 5 & -300 & 0.025 & 20 & 0.14 & 0.4 & 22 \\
\hline & 30 & 1.0 & 0.0021 & 55 & 5 & -300 & -0.025 & 20 & 0.16 & 0.04 & 24 \\
\hline \multirow[t]{3}{*}{19} & 46 & 2.0 & 0.0021 & 5 & 2 & -300 & 0 & - & 1.57 & 14.9 & 22 \\
\hline & 47 & 2.0 & 0.0021 & 5 & 2 & -300 & 0.05 & 20 & 2.08 & 10.7 & 26 \\
\hline & 48 & 2.0 & 0.0021 & 5 & 2 & -300 & -0.05 & 20 & 0.69 & 10.8 & 20 \\
\hline 20 & 43 & 2.0 & 0.0021 & 5 & 10 & -300 & 0 & - & 0.90 & 15.0 & 14 \\
\hline & 44 & 2.0 & 0.0021 & 5 & 10 & -300 & 0.05 & 20 & 0.99 & 11.5 & 16 \\
\hline & 45 & 2.0 & 0.0021 & 5 & 10 & -300 & -0.05 & 20 & 0.36 & 10.7 & 13 \\
\hline 21 & 38 & 2.0 & 0.0021 & 5 & 5 & -300 & 0 & - & 1.10 & 15.5 & 16 \\
\hline & 42 & 2.0 & 0.0021 & 5 & 5 & -300 & 0.10 & 20 & 1.28 & 7.2 & 19 \\
\hline & 41 & 2.0 & 0.0021 & 5 & 5 & -300 & -0.10 & 20 & 0.20 & 7.6 & 17 \\
\hline 22 & 50 & 2.0 & 0.0021 & 5 & 5 & -430 & 0 & - & 1.37 & 17.6 & 19 \\
\hline & 51 & 2.0 & 0.0021 & 5 & 5 & -430 & 0.05 & 20 & 1.64 & 14.5 & 18 \\
\hline & 49 & 2.0 & 0.0021 & 5 & 5 & -430 & -0.05 & 20 & 0.67 & 17.6 & 17 \\
\hline 23 & $21^{\mathrm{a}}$ & 1.0 & 0.0021 & 5 & 5 & -300 & 0 & - & 1.08 & 8.4 & 29 \\
\hline & $22^{\mathrm{a}}$ & 1.0 & 0.0021 & 5 & 5 & -300 & 0.05 & 20 & 1.13 & 5.3 & 30. \\
\hline
\end{tabular}


TABLE 1. (Continued)

\begin{tabular}{|c|c|c|c|c|c|c|c|c|c|c|c|}
\hline Triad & Run & $f\left(\times 10^{4} \mathrm{~s}^{-1}\right)$ & $\alpha_{1}$ & $h_{0}(\mathrm{~m})$ & $r\left(\times 10^{4} \mathrm{~s}^{-1}\right)$ & $Q\left(\mathrm{~W} \mathrm{~m}^{-2}\right)$ & $\tau_{A}\left(\mathrm{~N} \mathrm{~m}^{-2}\right)$ & $t_{1}$ (days) & $\operatorname{EKE}\left(\times 100 \mathrm{~m}^{2} \mathrm{~s}^{-2}\right)$ & $N^{2}\left(\times 10^{5} \mathrm{~s}^{-2}\right)$ & $\lambda(\mathrm{km})$ \\
\hline & $23^{\mathrm{a}}$ & 1.0 & 0.0021 & 5 & 5 & -300 & -0.05 & 20 & 0.49 & 5.9 & 37 \\
\hline \multirow[t]{3}{*}{24} & $35^{\mathrm{a}}$ & 0.5 & 0.0021 & 5 & 5 & -300 & 0 & - & 0.95 & 5.3 & 38 \\
\hline & $37^{\mathrm{a}}$ & 0.5 & 0.0021 & 5 & 5 & -300 & 0.05 & 20 & 1.05 & 3.0 & 36 \\
\hline & $36^{\mathrm{a}}$ & 0.5 & 0.0021 & 5 & 5 & -300 & -0.05 & 20 & 0.42 & 3.6 & 38 \\
\hline \multirow[t]{3}{*}{25} & 1 & 1.0 & 0.0021 & 5 & 5 & -300 & 0 & - & 0.87 & 6.0 & 29 \\
\hline & $61^{\mathrm{b}}$ & 1.0 & 0.0021 & 5 & 5 & -300 & 0.05 & 20 & 0.86 & 8.0 & 25 \\
\hline & $60^{c}$ & 1.0 & 0.0021 & 5 & 5 & -300 & -0.05 & 20 & 0.86 & 6.3 & 31 \\
\hline \multirow[t]{3}{*}{26} & $57^{\mathrm{d}}$ & 1.0 & 0.0021 & 5 & 5 & -300 & 0.05 & 20 & 0.71 & 6.1 & 25 \\
\hline & $58^{\mathrm{e}}$ & 1.0 & 0.0021 & 5 & 5 & -300 & 0.05 & 20 & 0.71 & 7.4 & 25 \\
\hline & $59^{\mathrm{f}}$ & 1.0 & 0.0021 & 5 & 5 & -300 & 0.05 & 20 & 0.86 & 6.8 & 41 \\
\hline
\end{tabular}

${ }^{\text {a }}$ Different initial stratification than runs $1-3$ or $13-15$.

${ }^{\mathrm{b}}$ Cross-shelf winds with $\tau^{x}>0$.

${ }^{\mathrm{c}}$ Cross-shelf winds with $\tau^{x}<0$.

${ }^{\mathrm{d}}$ Oscillating forcing with a 10-day period.

${ }^{\mathrm{e}}$ Oscillating forcing with a 5-day period.

${ }^{\mathrm{f}}$ Oscillating forcing with a 2-day period.

$$
\begin{aligned}
C_{\mathrm{MKE} \rightarrow \mathrm{EKE}}= & -\frac{1}{A} \int_{0}^{W} \int_{-h}^{0}\left(\left\{v_{x}\right\}\left\{u^{\prime} v^{\prime}\right\}+\left\{v_{z}\right\}\left\{w^{\prime} v^{\prime}\right\}\right. \\
& \left.+\left\{u_{x}\right\}\left\{u^{\prime} u^{\prime}\right\}+\left\{u_{z}\right\}\left\{w^{\prime} u^{\prime}\right\}\right) d z d x .
\end{aligned}
$$

The eddy contribution $\left\{w^{\prime} \rho^{\prime}\right\}$ to (6a) is expected to be important when baroclinic instability is in progress. The kinetic energy conversion equation $[(6 b)]$ is typically dominated by the two terms that involve along-channel mean flow $\{v\}$. The terms involving horizontal Reynolds stresses are indicative of barotropic instability, while terms involving vertical Reynolds stresses are indicative of vertical shear instability. In addition, the turbulent frictional dissipation

$$
C_{\mathrm{EKE} \rightarrow \mathrm{DISS}}=\frac{1}{A} \int_{0}^{W} \int_{-h}^{0}\left\{u^{\prime}\left(D u_{z}^{\prime}\right)_{z}+v^{\prime}\left(D v_{z}^{\prime}\right)_{z}\right\} d z d x \equiv \Theta
$$

is a valuable diagnostic. There are several other terms in the EKE budget, all having to do with the energy flux across the open boundary at $x=W$. Although these fluxes are always calculated for each run, they are generally negligible compared to EKE creation and dissipation.

APE is the difference between the actual potential energy [(5d)] and the potential energy if density is conserved, but all isopycnals are flat. In practice, this calculation is done by a sorting methodology similar to that in Winters et al. (1995). For each $x \leq W$ grid point, its related volume is computed. Then the densest water with $x \leq W$ is found and placed in the bottom of the basin segment bounded offshore by $x=W$, while conserving volume. The next densest water parcel is then found and deposited above the densest and so on until all grid points are accounted for. The resulting density field has flat isopycnals, and its PE is then computed. The difference between the two PE estimates is then APE.

The flow field's typical alongshore wavelength $\lambda$ is estimated using the autocovariance of cross-shelf velocity $u$ centered on $x=12.5 \mathrm{~km}=W / 2$ and within $\pm 1 \mathrm{~km}$ in $x$. An autocovariance function (vs alongshore lag) is computed for multiple depths at the central location and at middepth only at the neighboring locations. These functions are averaged together. The wavelength is then taken to be 4 times the lag of the first zero crossing of the average autocovariance function. This approach is a sensible way to detect the wavelength if the flow is fairly monochromatic in $y$ and seems to give sensible results even in the presence

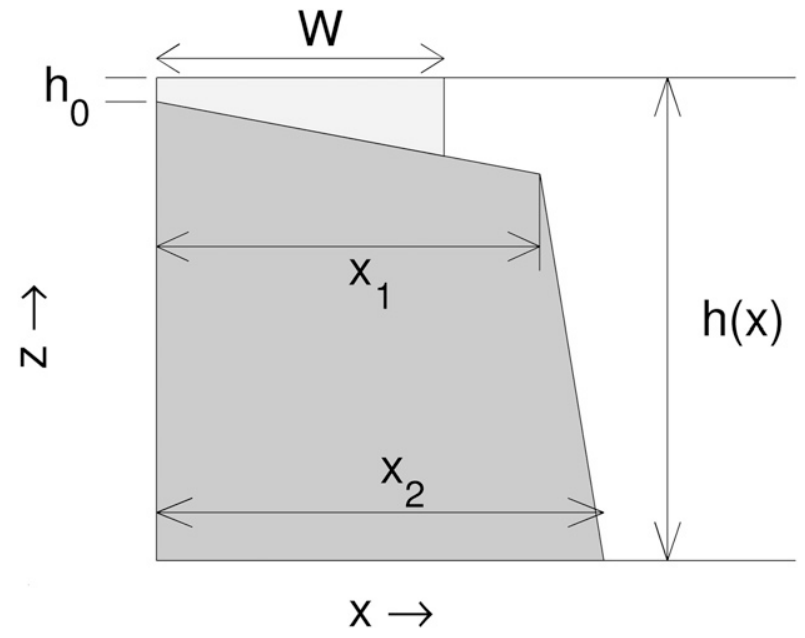

FIG. 1. Schematic of the model geometry. The lightly shaded area represents the region $(x<W)$ over which diagnostics are computed. For all runs, $x_{1}=30 \mathrm{~km}, x_{2}=40 \mathrm{~km}$, and $W=25 \mathrm{~km}$. 

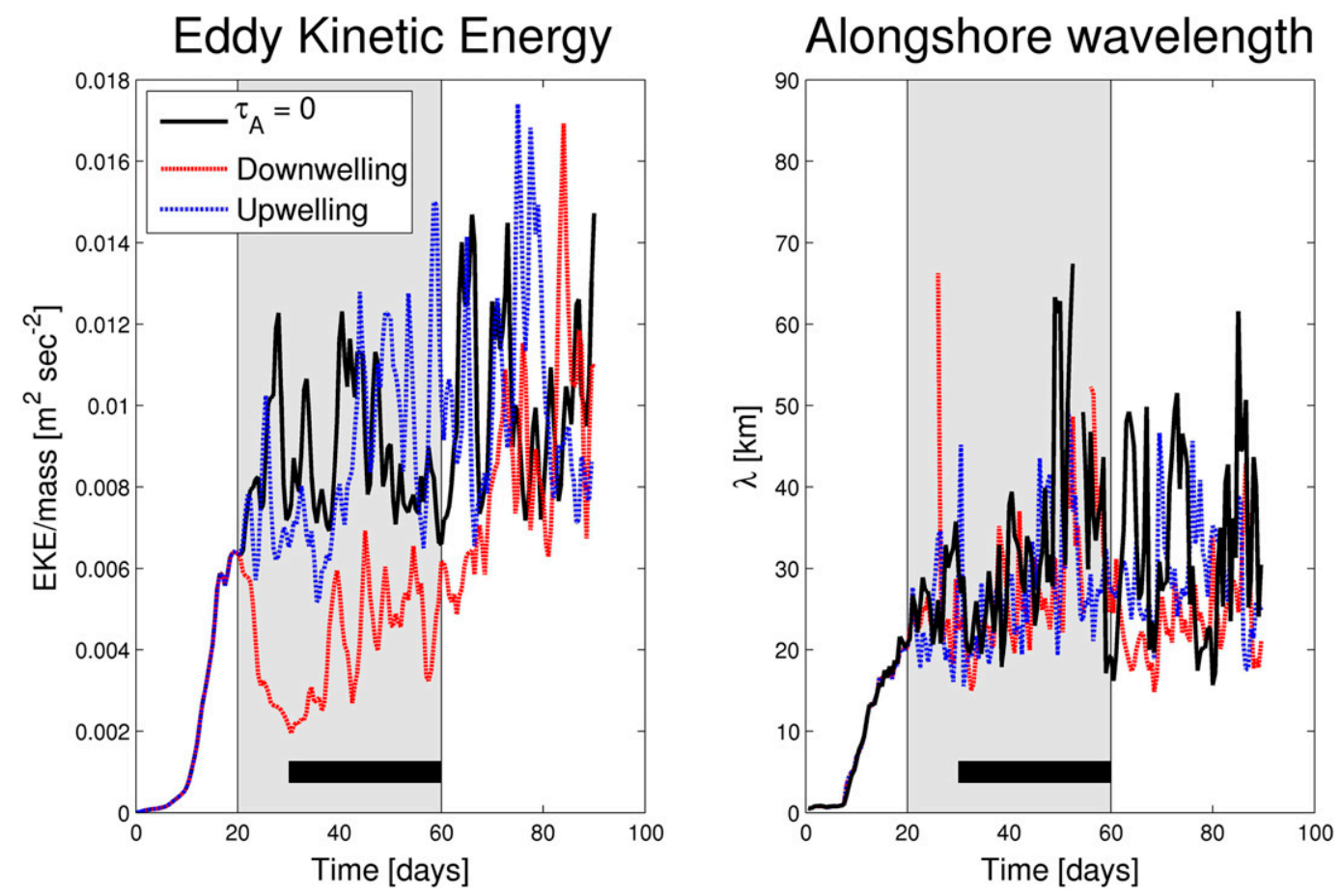

FIG. 2. (left) Volume-averaged EKE as a function of time for runs 1 ( $\tau_{A}=0$, black), 2 (upwelling, blue), and 3 (downwelling, red) of triad 1 . The shaded area is the interval where the wind stress was present, and the black bar indicates the time over which volume averages were computed. (right) The same, only showing alongshore wavelength $\lambda$ at $x=12.5 \mathrm{~km}$.

of a continuum of scales, as is typically the case in an eddy field. The along-channel mean buoyancy frequency squared $\left\{N^{2}\right\}$ is also evaluated at $x=W / 2$, using the difference between mean surface and bottom densities.

Inspection of the various model runs (e.g., Fig. 2) shows that the flow field and EKE in particular generally adjust to the applied wind forcing within about 5-10 days. Thus, the presumably adjusted time interval $t=30-60$ days (the solid bar in Fig. 2) is used for computing time-averaged EKE, length scale, and so on as summarized in Table 1. For this time window, the mean flow and eddy fields (as evidenced by MKE, EKE, or mean cross-shelf density gradients), are taken to have reached a statistically steady state for all runs except for run 9 (triad 6), which has no bottom friction at all [although interior dissipation contributes substantially in (6c)]. Even in this case, EKE is no longer increasing by the end of this time interval.

\section{Results}

\section{a. No wind forcing}

All model runs lead to instabilities and the growth of an active eddy field over the shelf (e.g., Fig. 3). To establish a basis of comparison, however, discussion initially focuses on a representative case $(\operatorname{triad} 1, \operatorname{run} 1$ :
Table 1) with no wind forcing. In some regards, the results here are anticipated by Pringle (2001). Initially, surface cooling leads to virtually vertical isopycnals over the shelf and an almost linearly increasing APE (Fig. 4). For the first several days of the model run, the flow field is dominated by small-scale, $0.5-\mathrm{km}$ "chimneys" that penetrate downward from the surface to depths up to $60 \mathrm{~m}$. A baroclinic (Fig. 5) instability, most visible in the $u$ field, begins to develop nearshore by around day 6 of the model run, and the initial alongshore wavelength is about 1-2 km (Fig. 2). After around day 8, the EKE begins to grow more rapidly and $\lambda$ begins an almost linear increase until around day 20-25 (Fig. 2). APE (Fig. 4) continues to grow until around day 12, when the growing eddy field is sufficiently large to affect the mean isotherm slope, hence APE. After this time, APE fluctuates somewhat with time but appears to have reached a plateau, where APE is consumed by instabilities about as quickly as it is generated by the surface cooling. By around day 20-25, $\lambda$ at $x=12.5 \mathrm{~km}$ and EKE also appear to reach a rather noisy plateau. Upon equilibration, both $\overline{\mathrm{eke}(x, t)}$ (the depth-averaged local eke) and $\lambda$ increase slowly offshore, $\lambda$ being roughly proportional to $\overline{\mathrm{eke}}^{1 / 2}$.

The fully developed flow field (Fig. 3) is characterized by energetic (speeds up to $0.5 \mathrm{~m} \mathrm{~s}^{-1}$ ) eddies embedded 


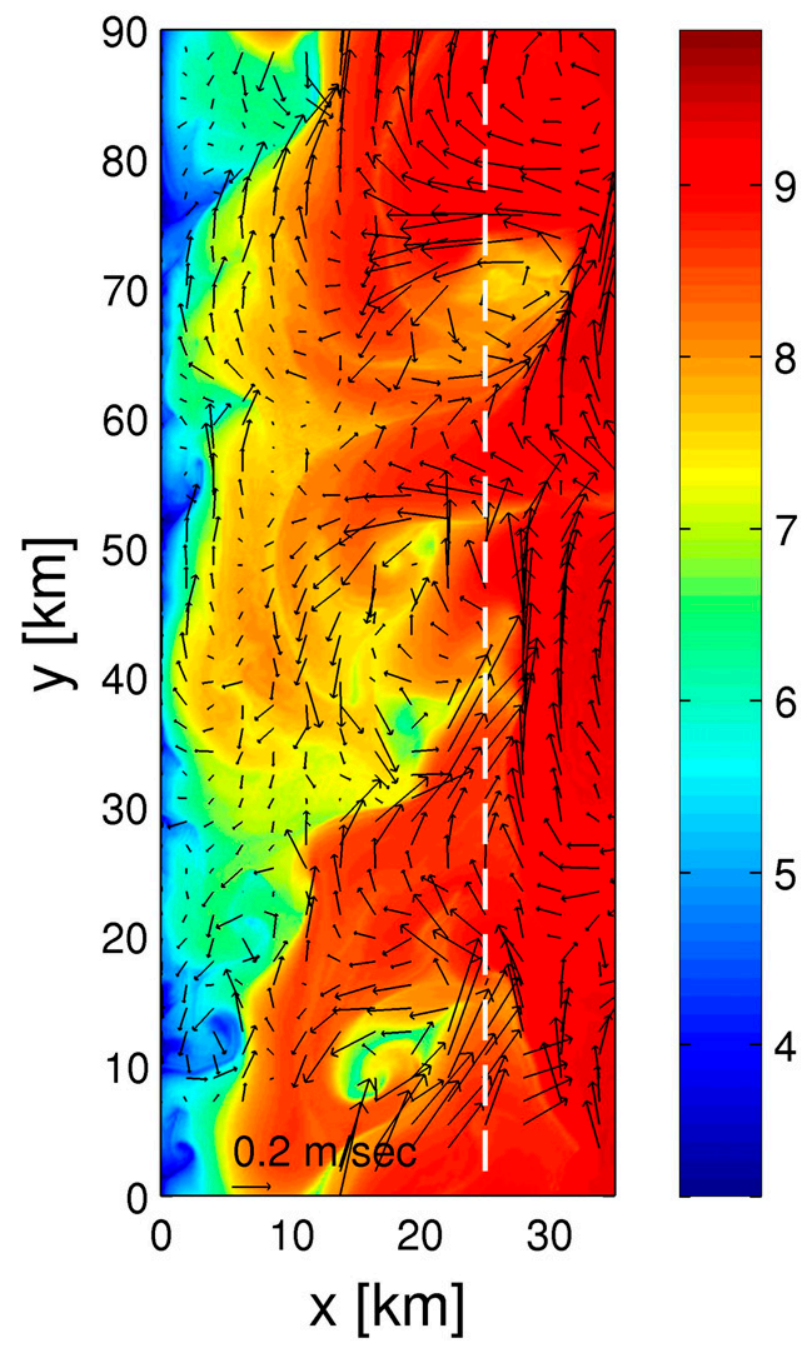

FIG. 3. Surface temperature (color, ${ }^{\circ} \mathrm{C}$ ) and velocity (arrows) for run 1 at $t=40$ days. The white, dashed line indicates $x=$ $25 \mathrm{~km}$, the offshore boundary of the volume over which statistics were computed.

in a weaker, positive (in the sense expected based on thermal wind balance) alongshore flow. Close inspection shows fronts and regions of very sharp velocity gradients: Rossby numbers of $O(1)$ are found frequently. When the $T$ and $v$ fields are averaged over days 30-60 and over a channel length (Fig. 6), the mean alongshore flow becomes apparent, and it is clear that the isotherms are no longer vertical but slope downward offshore. This tilt is expected as a result of an eddy field driven by baroclinic instability, and it is, of course, consistent with APE being depleted. There is also a mean cross-shelf flow (Fig. 7), with downslope flow in the lowermost $10 \mathrm{~m}$ and a weaker, compensating onshore flow in the upper $15 \mathrm{~m}$ at the $32-\mathrm{m}$ isobath. Both the mean flow and the eddy field convey heat toward the coast (where the

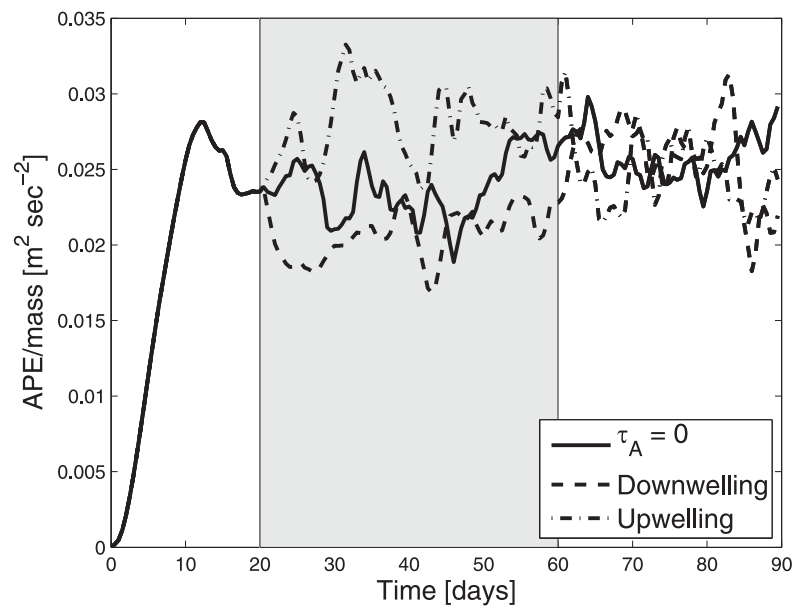

FIG. 4. Volume-averaged APE as a function of time for runs 1 $\left(\tau_{A}=0\right), 2$ (upwelling), and 3 (downwelling). The conventions are as in Fig. 2.

coldest waters reside), although, for this example, the eddies transport about 5 times as much as the mean flow at this isobath. For runs with no applied wind stress, the energy exchanges [(6a)-(6c); Figs. 5, 11], averaged over the inner $25 \mathrm{~km}$ of the shelf, show that the instability in all cases is overwhelmingly baroclinic [(6a)]. Further study of the energetics shows that, averaged over days 30-60, the generation of EKE due to baroclinic instability is roughly balanced by dissipation within the control

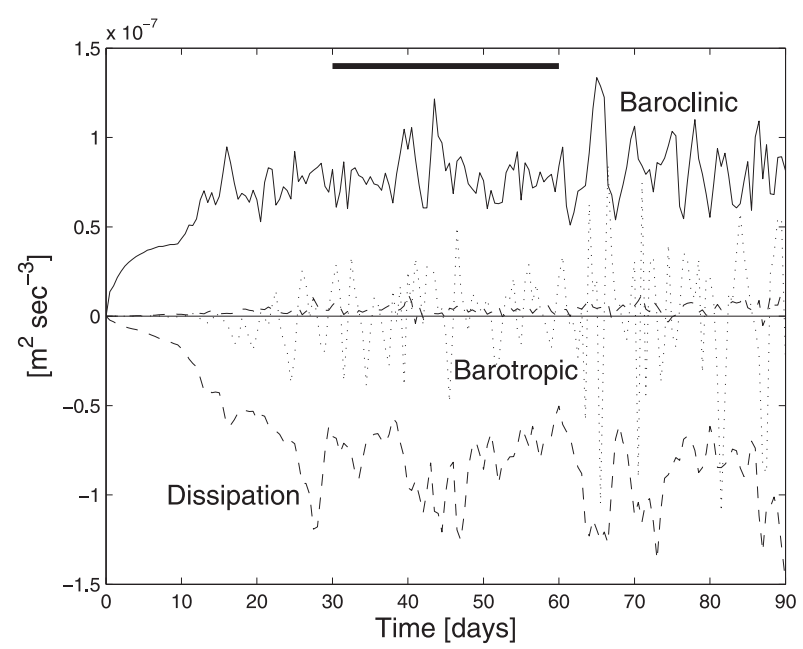

FIG. 5. Time series of EKE conversions for run 1. Solid line indicates eddy PE to KE conversion, dotted line (labeled dissipation) indicates the total EKE dissipation associated with vertical turbulent process (both at and above the bottom boundary), light dotted line (labeled barotropic) indicates MKE to EKE conversion due to terms involving $\left\{v_{x}\right\}$, and the remaining dotted line (unlabeled) indicates MKE to EKE conversion due to terms involving $\left\{v_{z}\right\}$. The heavy horizontal line at the top of the plot shows the 30-60-day window over which mean quantities are computed. 


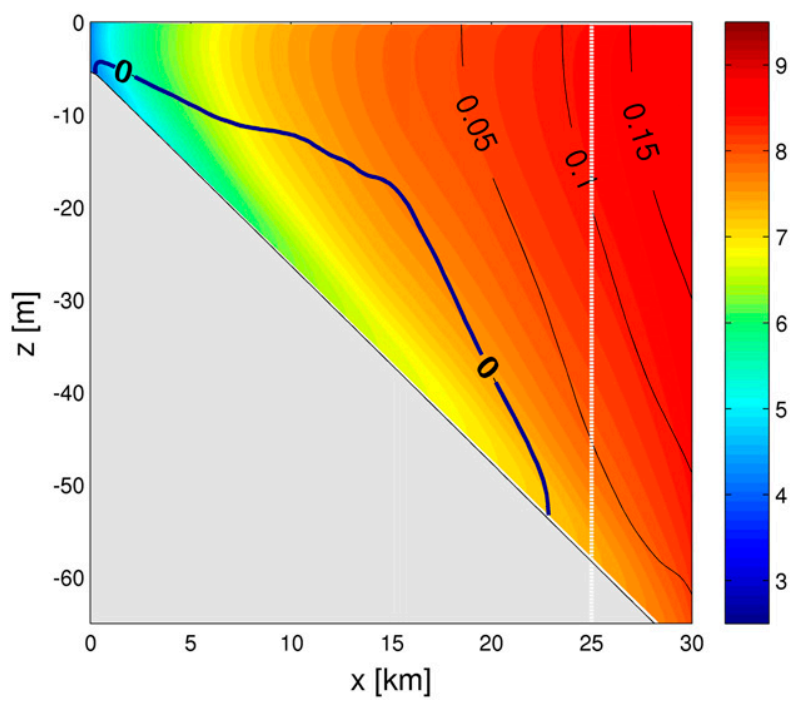

FIG. 6. Along-channel and time (30-60 days) averages of temperature (color, ${ }^{\circ} \mathrm{C}$ ) and alongshore velocity $v$ (contours, $\mathrm{m} \mathrm{s}^{-1}$ ) for run 1 with $\tau_{A}=0$. The white dotted line at $x=25 \mathrm{~km}$ indicates the offshore edge of the region over which EKE and APE are computed.

volume (primarily at the bottom or within the bottom boundary layer). Energy fluxes across the open offshore boundary at $x=25 \mathrm{~km}$ are generally negligible.

Run 1, which has been discussed so far, is typical of cases where there is no wind stress. This is so in terms of both the qualitative progression of events as well as of the general timing. Runs do vary, of course, from one case to another. For example, when the surface cooling is weaker $\left(\tau_{A}=0\right.$ members of triads 13 and $\left.14 \mathrm{vs} 1\right)$, EKE falls off markedly. Also, when the coastal depth $h_{0}$ increases, EKE decreases (e.g., $\tau_{A}=0$ members of triad 17 vs 1 ), a result that seems intuitive in that the fractional depth difference decreases and so the offshore temperature gradient should be weaker. In other cases, such as for varying $f$ or $\alpha_{1}\left(\tau_{A}=0\right.$ members of triads 1 vs 11 and $12 ; 1$ vs 15 and 16 ), the trends are not so obvious, a finding rationalized by section $4 \mathrm{e}$ below. In all model runs, eddy dissipation [(6c)] averaged over 30 days is the primary term balancing the input of EKE due to instability. For example, for the runs with $\tau_{A}=0$, the average (over all of these model runs) of the 30-day mean EKE input [(6a)] divided by 30 -day mean dissipation $[(6 c)]$ is -0.99 .

The role of bottom friction requires more consideration. Runs with smaller $r$ (e.g., compare run 9 of triad 6 vs 1) have larger EKE, although larger bottom friction (run 53 of triad 10 vs 1 ) has little effect on EKE. This result is illustrated in Fig. 8, which summarizes 5 runs that are identical except for the strength of the bottom frictional parameter. Further, the inset drawings illustrate the midshelf most energetic empirical orthogonal function

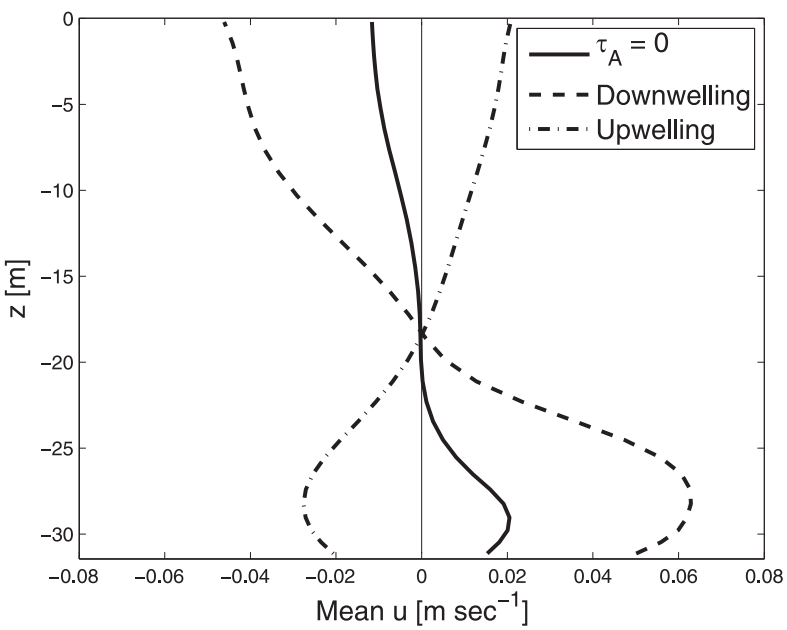

FIG. 7. Alongshore and time (30-60 days) means of cross-shelf velocity $u$ at $x=12.5 \mathrm{~km}$. Profiles are shown for runs $1\left(\tau_{A}=0\right)$, 2 (upwelling), and 3 (downwelling).

(EOF; computed at $x=12.5 \mathrm{~km}$ using all $y$ information for all times between 30 and 60 days) for cross-shelf velocity weighted by the square root of its modal variance. These modes represent $87 \%-94 \%$ of the total cross-shelf velocity variance. This presentation thus conveys information about both structure and amplitude. When there is no bottom friction, the mode is essentially barotropic, and the alongshore current amplitude (not shown) is about twice the cross-shelf amplitude. As $r$ increases, the flow

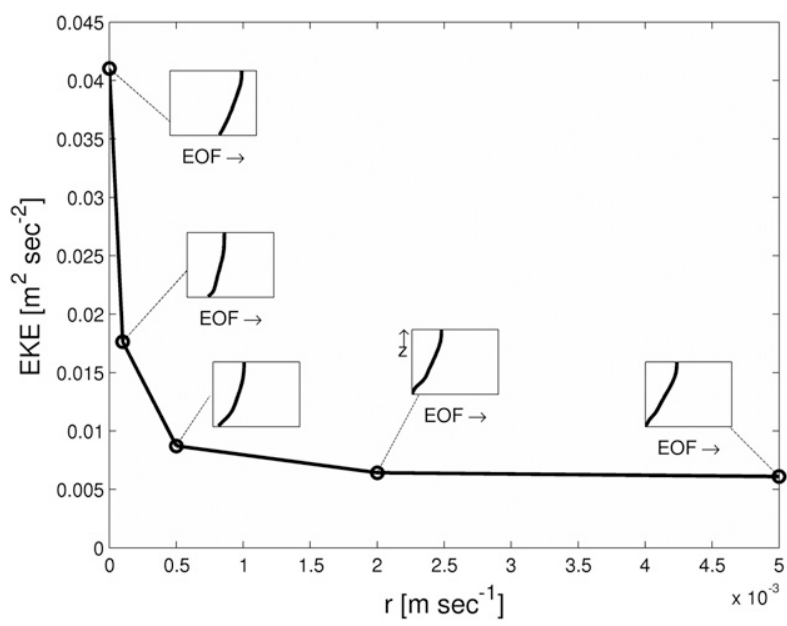

FIG. 8. Volume- and time-averaged (30-60 days) EKE as a function of bottom frictional resistance parameter $r$. The runs $(9$, $6,1,29$, and 53 from left to right) are identical except for this parameter, and all have $\tau_{A}=0$. For each run, the vertical profile of the most energetic EOF of $u$ at $x=12.5 \mathrm{~km}$ is shown, weighted by the square root of its eigenvalue. Thus, the amplitude of the mode is roughly proportional to the standard deviation of $u$. Although the EOF axes are not labeled, the scaling is consistent from one subplot to the next. 

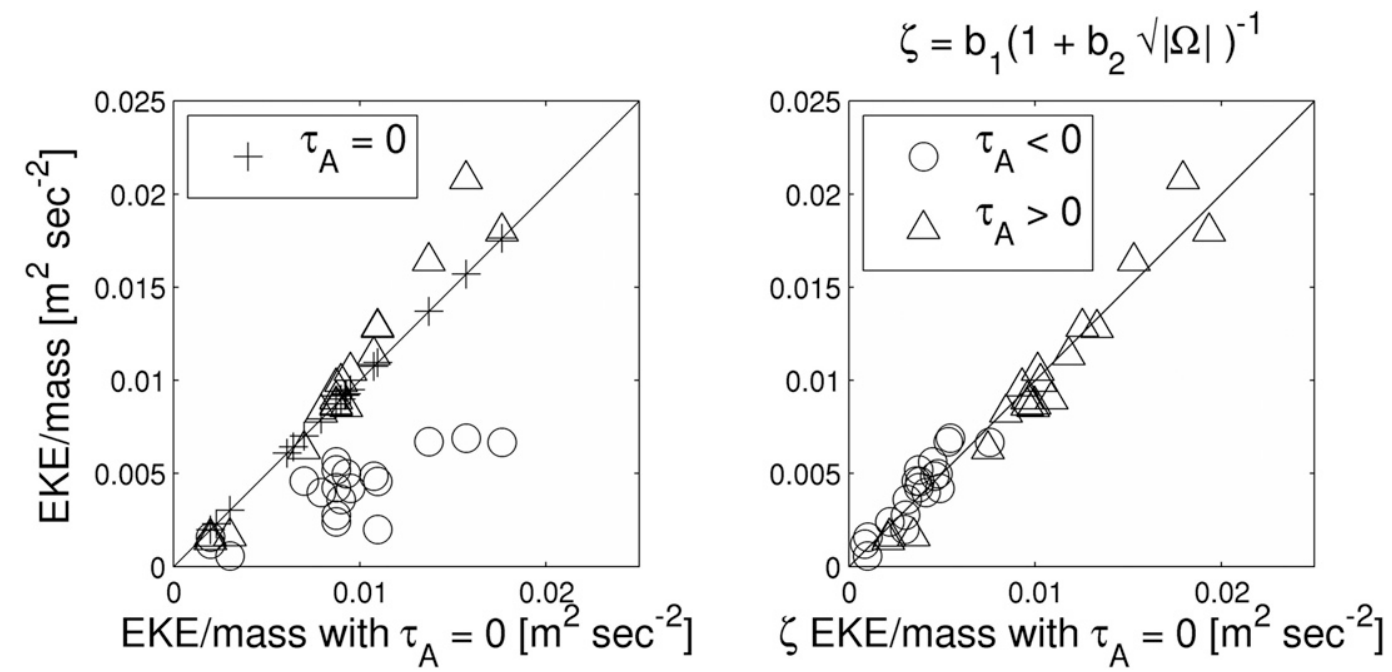

FIG. 9. (left) Scatterplot of volume- and time-averaged EKE for runs with no wind stress (crosses) vs otherwise identical runs with upwelling-favorable wind stress (triangles) and opposite and equal downwelling-favorable wind stress (circles). (right) The same but after values for the runs with nonzero wind stress have been corrected with (10).

rapidly becomes more isotropic, and the sensitivity to $r$ is almost nil for $r>5 \times 10^{-4} \mathrm{~m} \mathrm{~s}^{-1}$. This lack of sensitivity for larger $r$ (larger in the sense that the barotropic spindown time $h / r \leq 0.8$ days at $x=12.5 \mathrm{~km}$ ) is accompanied by a change in the vertical structure of the currents: velocity is nearly zero at the bottom, and amplitude increases gradually upward through the water column. The bottom boundary layer here is only about $10 \mathrm{~m}$ thick, so that this shear is largely balanced by adiabatic rather than frictional effects. All considered, it appears that the eddies have experienced stratified spindown (e.g., Holton 1965a,b). What is really interesting about this flow structure is that, even though the velocity is weak at the bottom, it is always large enough to allow frictional dissipation to be a leading-order term (and always the primary sink) in the EKE budget. Put another way, the near-bottom velocity decreases with an increasing frictional coefficient, but it does it in such a way that the near-bottom dissipation (e.g., Fig. 5) remains energetically important (unless $r=0$, in which case interior dissipation dominates).

\section{b. Alongshore wind stress}

Including a steady alongshore wind stress for days 20-60 (but keeping all other parameters constant) changes the results in ways largely consistent with original expectations. After an adjustment time of about 5 days or less, both EKE and APE (Figs. 2, 4) decrease substantially in the presence of downwelling-favorable (negative) winds. With upwelling-favorable winds, any EKE effect is less obvious, but APE is enhanced. Considering all of the run triads (Fig. 9, left panel), it is clear that downwellingfavorable winds always decrease EKE to some extent, while upwelling-favorable winds can generate a modest enhancement of EKE. After the winds cease, the energy pools return within a few days to states indistinguishable from those with no wind stress (e.g., Fig. 2). Any wind influence on the alongshore wavelength is not at all apparent from plots such as Fig. 2b.

The mean sections are strikingly modified by the winds. Downwelling-favorable (negative) winds (Fig. 10a) tend to create a negative alongshore shear and alongshore flow. This sense of shear is counter to the thermal wind shear in the absence of winds (Fig. 6). The net effect is a decreased mean shear, but a substantial $\left(-0.15 \mathrm{~m} \mathrm{~s}^{-1}\right)$ alongshore flow. Although there remains a clear crossshelf temperature gradient, isotherms are somewhat flattened so as to create gravitationally stable stratification: a classic result of baroclinic instability. Upwellingfavorable winds (Fig. 10b) drive a strongly positive $v$ and $v_{z}$ and thus act to enhance the positive vertical shear that would otherwise be present (Fig. 6).

Considering the energy transfers that create EKE for all run triads (of zero, positive, and negative winds; Fig. 11), a clear pattern emerges. Upwelling-favorable winds are related to enhanced (positive) MKE to EKE transfer, which is primarily the result of the $\left\{v_{z}\right\}$ term in (6b) creating EKE (and decreasing MKE) due to a vertical shear instability. Thus, shear instability with upwelling tends to enhance EKE substantially. On the other hand, downwelling-favorable (negative) winds are associated with a net transfer from EKE to MKE 

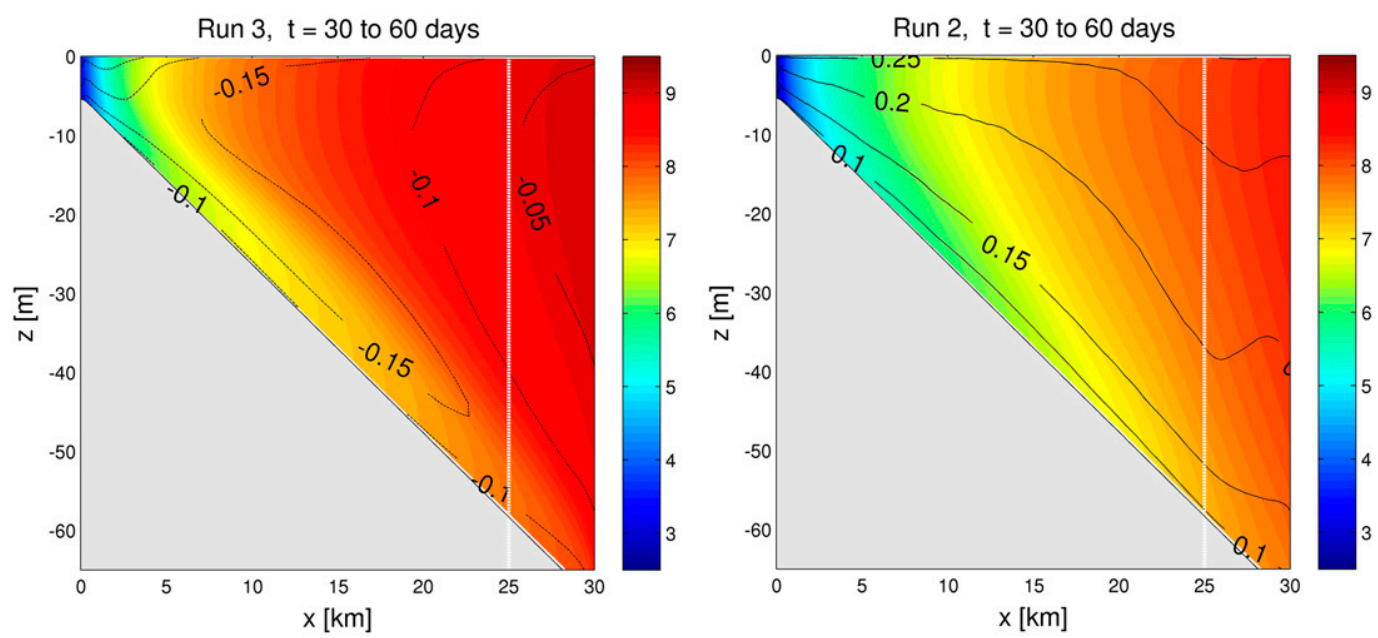

FIG. 10. Alongshore and time-mean (30-60 days) sections of temperature (color, ${ }^{\circ} \mathrm{C}$ ) and alongshore velocity (contours, $\mathrm{m} \mathrm{s}^{-1}$ ) for first triad runs with (left) downwelling-favorable winds (run 3) and (right) equal and opposite upwelling-favorable winds (run 2). The conventions are as in Fig. 6.

associated primarily with the $\left\{\boldsymbol{v}_{x}\right\}$ term in (6b). Thus, not only does EKE decrease due to a decreased APE pool, but eddy energy faces an additional loss to MKE when $\tau_{A}<0$, presumably related to an inverse cascade effect.

Some wind effects are summarized in Fig. 12, which shows diagnostics as a function of $\tau_{A}$ for a group of runs where all parameters other than wind stress are held constant. The reduction in EKE for negative wind stress is rather evident, and for these runs, there is no obvious EKE enhancement for positive winds. The midshelf stratification decreases as the magnitude of wind stress increases. Dominant wavelength decreases slightly for larger wind magnitudes but not as dramatically as the effect for stratification. All of these effects are treated in more detail below.

\section{c. Other wind configurations}

Three model runs (triad 26, runs 57, 58, 59; Table 1 ) are executed with sinusoidally oscillating alongshore winds over days 20-60. All three runs have a wind stress amplitude of $0.05 \mathrm{~N} \mathrm{~m}^{-2}$, and only the oscillation period differs from run to run. Aside from the wind forcing, the model configuration is the same as that in runs $1-3$. For run 59, with a 2-day period, EKE is indistinguishable from that in run 1 , which has $\tau_{A}=0$. This is not surprising in that the EKE response time to wind forcing (e.g., Fig. 2) typically appears to be about 5 days, so that this run's frequent reversals yield little net effect. For longer periods (10 and 5 days for runs 57 and 58, respectively), there is an EKE decrease to $0.71 \times 10^{-2} \mathrm{~m}^{2} \mathrm{~s}^{-2}$, compared to $0.87 \times$ $10^{-2} \mathrm{~m}^{2} \mathrm{~s}^{-2}$ when there is no wind stress. This reduction is not as substantial as when a steady negative wind stress of the same amplitude is applied $\left(0.42 \times 10^{-2} \mathrm{~m}^{2} \mathrm{~s}^{-2}\right.$ for run $3)$. It is tempting to interpret this intermediate reduction as a reflection of a quasi-steady response: decreased EKE during the negative phase of the wind cycle but no substantial effect during the positive phase. What is curious here, however, is the extreme similarity of the EKE and $\lambda$ results for periods of 5 and 10 days (runs 58 and 57). It is worth adding that, for runs with oscillating winds (i.e., a time-dependent, large-scale wind forcing), computing alongshore correlation scales for pressure and for the $u$ and $v$ velocity components (as in Kundu and Allen 1976) yields results qualitatively very similar to those in Brink and Seo (2016); alongshore currents and sea level are correlated over much greater alongshore separations than are cross-shelf currents.

Two cases (triad 25, runs 60 and 61) are executed with uniform cross-shelf winds having the time dependence [(3)]. Again, both runs are the same as runs 1-3 except for the wind forcings. For both offshore (run 61) and onshore (run 60) winds, EKE is essentially the same $\left(0.86 \times 10^{-2}\right.$ vs $0.87 \times 10^{-2} \mathrm{~m}^{2} \mathrm{~s}^{-2}$ ) as in case 1 with no wind stress at all. This is not surprising in that spatially uniform, steady, cross-shelf wind stresses are only expected to drive currents effectively in a shallow, nearshore region (e.g., Lentz and Fewings 2012). Farther offshore, the winds have no noticeable effect on mean mixed layer thickness, and the only expected wind-driven flow is alongshore Ekman transport, which has no effect on cross-shelf transports. Thus, it seems likely that from a shelfwide perspective, spatially uniform cross-shelf winds play a negligible role in eddy processes.

\section{Diagnostic relationships}

\section{a. Winds and EKE}

One way to estimate the relative importance of wind versus buoyancy forcing is to evaluate the relative 


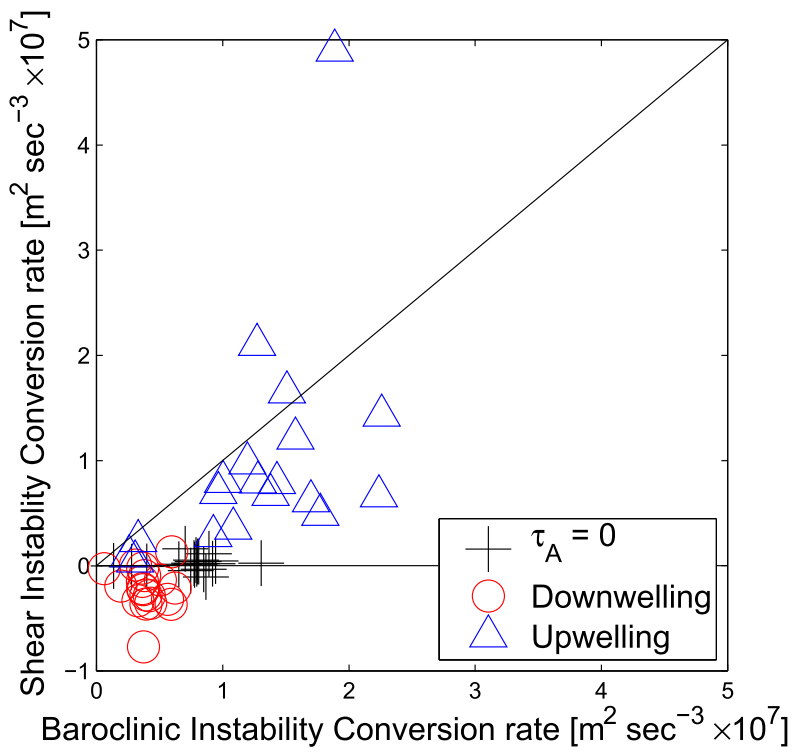

FIG. 11. Volume- and time-averaged (30-60 days) energy conversions for runs with upwelling-favorable winds (triangles) and downwellingfavorable winds. Positive values correspond to the creation of EKE. The horizontal axis is the eddy contribution to $(6 a)$ : the potential to eddy kinetic energy conversion associated with baroclinic instability. The vertical axis is the total conversion (6b) from mean kinetic energy to EKE and so includes both barotropic instability (which dominates the downwelling cases) and vertical shear instability (which dominates for the upwelling cases. For runs with no wind stress (plus signs), all results lie very nearly (within $0.16 \times 10^{-7} \mathrm{~m}^{2} \mathrm{~s}^{-3}$ ) on the horizontal (baroclinic instability) axis.

strength of the resulting alongshore currents that would occur in the absence of eddies. Actually, in the present context, it is more appropriate to think of this comparison as being between the vertical shears since this is relevant both to vertical shear instability and to baroclinic instability through the thermal wind equation.

The acceleration of an alongshore current by the wind is estimated [from a depth average of (1b), neglecting alongshore variability, nonlinearity, and bottom stress] as

$$
\left\langle v_{W t}\right\rangle=\tau_{A} /(\rho h),
$$

where the brackets $\langle q\rangle$ represent an estimate of the quantity $q$. Given surface cooling $Q$, the vertically averaged rate of temperature change in a vertically mixed, quiescent ocean is

$$
\left\langle T_{t}\right\rangle=Q /\left(\rho_{0} C_{p} h\right),
$$

where $C_{p}$ is the heat capacity. Using the linearized equation of state [(1f)],

$$
\left\langle\rho_{t}\right\rangle=-\beta Q /\left(C_{p} h\right) .
$$
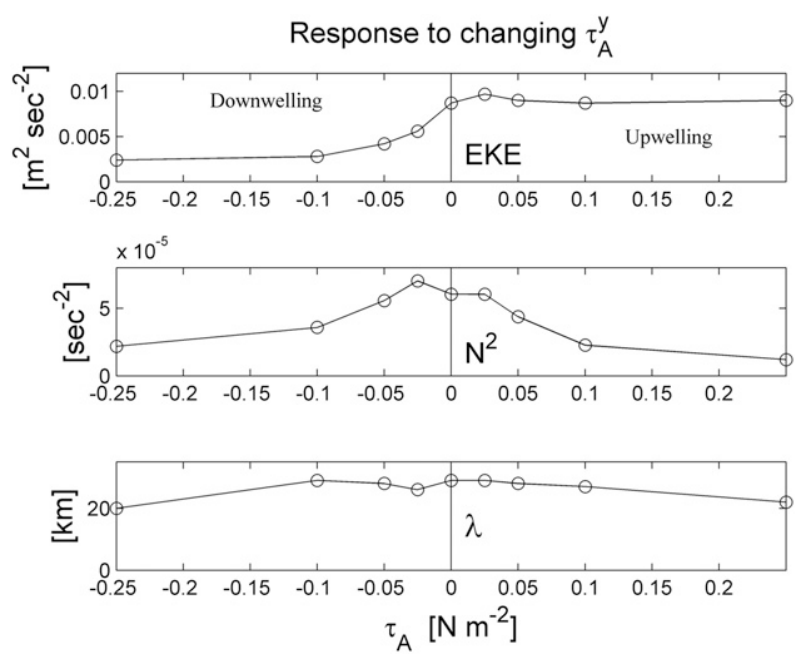

FIG. 12. The influence of alongshore wind stress amplitude $\tau_{A}$ on time-averaged (30-60 days) (top) EKE, (middle) $N^{2}$ at $x=12.5 \mathrm{~km}$, and (bottom) alongshore wavelength $\lambda$ at $x=12.5 \mathrm{~km}$. Circles indicate the actual values from model runs. This figure uses (from left to right) runs $43,4,3,28,1,27,2,5$, and 55 (triads $1-4$ ).

Thus, the cross-shelf density gradient for a quiescent ocean changes as

$$
\left\langle\rho_{x t}\right\rangle=\beta Q \alpha_{1} /\left(C_{p} h^{2}\right),
$$

so that applying the thermal wind equation and vertically integrating from $v=0$ at the bottom yield the alongshore acceleration due to cooling:

$$
\left\langle v_{C t}\right\rangle=-g \beta Q \alpha_{1} /\left(\rho_{0} f C_{p} h\right) .
$$

Thus, the importance of wind-driven shear relative to that driven by cooling is measured by

$$
\Omega=\frac{\left\langle v_{W t}\right\rangle}{\left\langle v_{C t}\right\rangle}=\frac{C_{p}}{g \beta} \frac{f \tau_{A}}{\alpha_{1}|Q|},
$$

a quantity that varies in magnitude between 0 and 100 for the runs in Table 1. Experimentation shows that the ratio $\Omega$ can be useful in collapsing the EKE results. Specifically, where $\mathrm{EKE}_{0}$ is the EKE for the $\tau_{A}=$ 0 member of a run triad, the functional form

$$
\langle\mathrm{EKE}\rangle=b_{1} \mathrm{EKE}_{0} /\left(1+b_{2}|\Omega|^{1 / 2}\right)
$$

is effective (Fig. 9, right panel). For $\tau_{A}<0$ (downwelling), $b_{1}=1.08, b_{2}=0.3$, and the correlation of the fit is 0.91 for 19 cases. When $\tau_{A}>0$ (upwelling), $b_{1}=0.98, b_{2}=-0.02$, and the correlation is 0.98 . Taking $b_{2}=0$ leads to a $7 \%$ increase in the error of the fit for $\tau_{A}>0$.

The estimate of (10) is based on the idea that the important physics is embedded in the roles played by 
wind- and cooling-induced vertical shears. There is a noteworthy asymmetry here, reflected in the coefficients $b_{2}$ for positive and negative $\tau_{A}$. A given negative wind stress is far more effective at inhibiting EKE than the same positive stress is for enhancing the eddy field. Downwelling decreases APE and the vertical shear's magnitude. On the other hand, upwelling enhances both vertical shear and APE (Fig. 4) so that increased EKE might be anticipated. The tendency for upwelling to advect dense water over light is expected to enhance mixing and dissipation relative to the cases with no wind or negative wind, and this is indeed the case in 18 out of 19 triads, often by about a factor of 2 (the one exception has about the same dissipation in all wind cases). Thus, the underlying cause of the $b_{2}$ asymmetry is apparently the enhanced role of dissipation during upwelling.

\section{b. Cross-shelf heat fluxes}

As long as cooling continues, the average water density in the control volume continues to increase for all runs. The onset of instability, hence eddy heat transport, acts only to slow the rate of densification slightly. Consequently, the average potential energy over the shelf continues to decrease at all times. Nonetheless, there is generally a substantial onshore heat transport during the 30-day sampling interval. With no wind stress (Fig. 13), the eddy heat flux at $x=12.5 \mathrm{~km}$ is typically about 4 times larger than the advective heat flux associated with the mean cross-shelf flow (Fig. 7). Steady winds, of course, drive an additional mean cross-shelf flow and hence modify the mean cross-shelf heat flux. For downwelling-favorable winds $(\Omega<0)$, the mean crossshelf heat transport strengthens, and the eddy heat flux weakens relatively until $|\Omega|>50$. This result is consistent, for $|\Omega|<50$, with the idea that downwelling circulation decreases APE and so, ultimately, weakens the eddy field. Likewise, for positive (upwelling) wind stress, the mean flow transports heat offshore, and the onshore eddy heat flux strengthens in compensation so that there is still a net onshore heat flux. For $|\Omega|>50$, the mean heat flux becomes strikingly less important than the eddy flux (the ratio of eddy to total flux approaches one). This modified behavior for large $|\Omega|$ is a reflection of the ocean at this location adjusting to "inner shelf" physics, where the entire water column is encompassed in a surface-to-bottom turbulent boundary layer (e.g., Lentz and Fewings 2012). Ekman transports are thus greatly reduced relative to bottom stress, and turbulent vertical stresses are significant throughout the water column. The reduction in Ekman transport leads to greatly reduced mean heat transport, even though eddy fluxes are hardly affected. The undiminished eddy heat transport might be

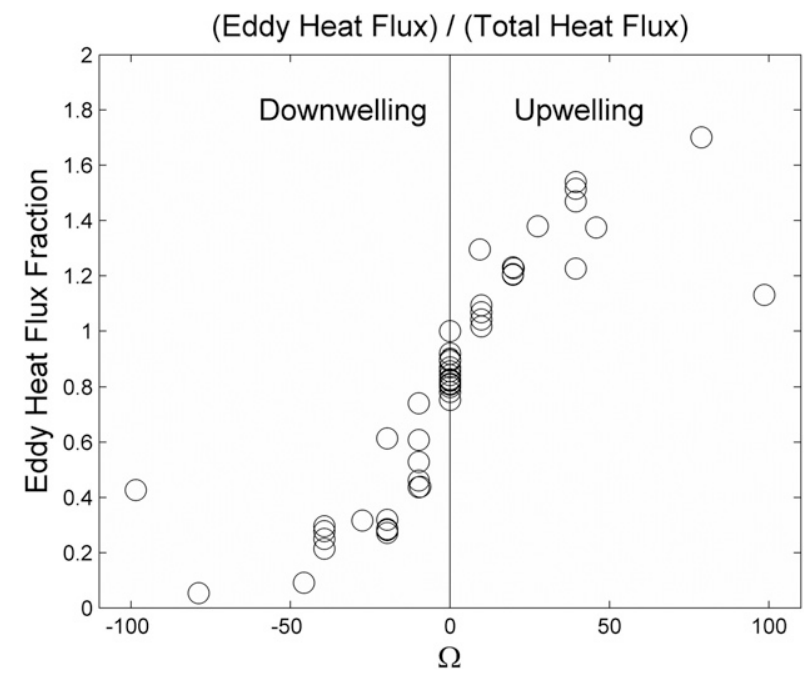

FIG. 13. The fraction of total cross-shelf heat transport due to eddy heat flux at $x=12.5 \mathrm{~km}$ as a function of the wind/cooling parameter $\Omega[(9)]$. A value of 1 indicates that all of the cross-shelf heat transport is due to eddy processes, and zero corresponds to all transport being due to mean flow transport. Values greater than 1 indicate that the mean flow transports heat offshore (upgradient).

anticipated from Fig. 8, which demonstrates that the eddy field is largely independent of bottom stress (hence Ekman physics) for realistically large $r$.

One might also ask about how vertical transports occur over the shelf. Whether winds are present or not, the mean vertical velocity (associated with flow structures as in Fig. 7) over the shelf is $O(1) \mathrm{m} \mathrm{day}^{-1}$ for most runs presented here. At the same time, the turbulent vertical exchange coefficient $B$ is very large, $>0.01 \mathrm{~m}^{2} \mathrm{~s}^{-1}$ in the gravitationally unstable upper $10-20 \mathrm{~m}$, and $O(0.002) \mathrm{m}^{2} \mathrm{~s}^{-1}$ deeper in the water column. As measured by a Péchlet number, these scales indicate that turbulent mixing is a more effective means of vertical transport than is advection. In addition, there is always an upward convective eddy flux $\left\{w^{\prime} T^{\prime}\right\}$ associated with baroclinic instability. The convective vertical heat flux is substantially greater (typically a factor of around 3 ) than turbulent diffusion when $\tau_{A} \geq 0$, and it is comparable when $\tau_{A}<0$. How relevant this vertical eddy flux might be for a passive tracer depends upon whether there is some reason for the tracer to be well correlated with temperature on eddy time scales (i.e., less than about a day). Vertical turbulent diffusion (measured by $B$ ) typically has time scales of $O(2)$ days and is always an important contributor to transport even in gravitationally stable portions of the shelf water column.

The application of oscillating alongshore winds or of steady cross-shelf winds does not affect the eddy versus mean heat flux question relative to the case with no winds 
at all; that is, these wind configurations do not generate any substantial mean heat flux at $x=12.5 \mathrm{~km}$.

\section{c. Alongshore wavelength}

For similar model runs with no wind stress, Pringle (2001) parameterized the dominant wavelength in his eddy field as the smaller of the topographic Rhines scale (which represents the maximum length scale in an inverse cascade and the scale at which topographic Rossby wave radiation begins; notation adapted to the present context)

$$
\lambda_{R}=d_{1}\left[H \mathrm{EKE}^{1 / 2} /\left(\alpha_{1} f\right)\right]^{1 / 2}
$$

or a frictional length scale

$$
\lambda_{F}=d_{2} H \mathrm{EKE}^{1 / 2} / r,
$$

where $d_{1}$ and $d_{2}$ are $O(1)$ constants found by fitting the model results. When this approach was attempted to fit the present $\tau_{A}=0$ calculated length scales $\lambda$, the best results were obtained by fitting with $\lambda_{R}$ only. This occurs even though the frictional parameter $r$ was varied from 0 to $5 \times 10^{-3} \mathrm{~m} \mathrm{~s}^{-1}$, a huge range. Another length scale that could conceivably enter is an inertial scale

$$
\lambda_{I}=d_{3} \mathrm{EKE}^{1 / 2} / f,
$$

although fitting the calculated $\lambda$ to the lesser of (11a) and (11c) again shows that $\lambda_{R}$ by itself is optimal for runs with no wind stress $\left(d_{1}=7.0\right.$, correlation $=0.95$, and the standard deviation of misfit $=2.8 \mathrm{~km}$ ). The inertial scale [(11c)] is consistent with the eddy field having a set Rossby number and (if the length scale is an internal Rossby radius of deformation) with a set gradient Richardson number.

Going through the same exercise separately for positive and negative winds shows that for $\tau_{A}<0$, the best results are obtained as

$$
\langle\lambda\rangle=\min \left(\lambda_{R}, \lambda_{I}\right),
$$

with $d_{1}=8.4$ and $d_{3}=67$ (correlation $=0.81$, misfit $=$ $4.4 \mathrm{~km}$ ). The $\lambda_{R}$ scale applies in 16 out of 19 cases. Using $\lambda_{R}$ alone would give a correlation of 0.73 and misfit of $5.3 \mathrm{~km}$. For $\tau_{A}>0,(12)$ is optimized with $d_{1}=6.7$ and $d_{3}=54$, a correlation of 0.91 and misfit of $3.0 \mathrm{~km}$. The $\lambda_{R}$ scale applies in 17 out of 19 cases. Using $\lambda_{R}$ alone in this case gives a correlation of 0.87 and error of $3.5 \mathrm{~km}$. Thus, a marginal improvement is had using the form (12) versus (11a) when $\tau_{A} \neq 0$.

Physically, the Rhines scale is the largest scale found in an EKE inverse cascade, and this is consistent with the finding that the eddy scale generally increases as EKE increases (Fig. 2) and that both reach a plateau at about the same time. It is not surprising when a barotropic eddy field evolves to a topographic Rhines scale, but the interesting thing about the present case is that, in most examples, the eddy field is distinctly surface intensified. The resolution is found by examining the scaling of the depth-integrated vorticity equation: the topographic Rhines scale is expected to apply as long as the bottom velocity for a given run is proportional to the depthaveraged flow, as it is here.

\section{d. Stratification}

In all model runs, the horizontal eddy heat transports lead to vertical stratification over the shelf. In cases with reasonably large bottom friction (Fig. 8), the eddy field is surface intensified and the velocity is quite small near the bottom. Thus, the vertical decay scale for the flow is the water depth $h$ except when $r$ is very small or zero. Since the shear is not frictionally balanced, it seems likely that the eddies conserve Ertel vorticity to some extent, and thus the vertical scale would be consistent with

$$
h \approx f \lambda /\left[N \varphi(\mu)^{1 / 2}\right],
$$

where $\varphi^{1 / 2}$ is some nondimensional function of the Ekman-like number $\mu=r /(f H)$ that accounts for the otherwise failure of (13) because the eddy flow becomes much more barotropic (the depth scale increases well beyond $h$ ) as $r \rightarrow 0$. Further, $\varphi^{1 / 2} \rightarrow$ constant as $\mu \rightarrow \infty$ and $\varphi^{1 / 2}$ is bounded as $\mu \rightarrow 0$.

If the horizontal scale $\lambda$ in (13) is taken to be simply the Rhines scale, then the stratification is estimated as

$$
\left\langle N^{2}\right\rangle=c_{1} f \mathrm{EKE}^{1 / 2} /\left(H \alpha_{1} \varphi\right) .
$$

After some experimentation, it is found that the functional form

$$
\varphi=1-c_{2} \exp \left(-c_{3} / \mu\right)
$$

works reasonably well in accounting for bottom friction. Specifically, for $\tau_{A}(<0,=0,>0), c_{1}=(0.26,0.25$, $0.11), c_{2}=(0.6,0.6,0.7)$, and $c_{3}=(0.009,0.02,0.008)$. The respective correlations of the fits are $(0.97,0.98,0.93)$ with misfit of $(1.21,0.92,1.55) \times 10^{-5} \mathrm{~s}^{-2}$. Not surprisingly, the best result is obtained for $\tau_{A}=0$, where the Rhines scale is consistently the best estimate for horizontal wavelength.

This scaling appears to be at variance with Fig. 12, where, for large positive $\tau_{A}, N^{2}$ falls off substantially even though EKE does not vary much over this range. The discrepancy is too great to be statistical scatter. It appears that this reduced stratification for strong winds is related to the switch to inner shelf behavior where turbulent processes are important throughout the water 
column. In these cases, the vertical turbulent mixing and stress are not weak, even at middepth. Thus, the low values of $N^{2}$ for large wind amplitudes appear to be due to enhanced wind-driven vertical mixing.

\section{e. EKE when $\tau_{A}=0$}

When no wind stress is present, the instability is essentially entirely baroclinic (Fig. 11), so it seems possible to develop a scaling for EKE for this case that is uncomplicated by barotropic or vertical shear effects. The starting point is to note that the two most important terms in the EKE budget are those due to dissipation and to the PE to EKE transfer [the eddy portion of (6a)], as in Fig. 5. It is then conjectured that the rate of APE addition to the system is balanced by $\Theta$, the eddy dissipation rate due to vertical turbulent processes [both internal and at the bottom boundary; (6c)]. That is to say that the rate of APE addition is proportional to the rate of EKE generation via baroclinic instability. The input of APE to the system is estimated as the maximum of $\mathrm{APE}_{t}$ over the time previous to its first temporal peak (on Fig. 4, at day 4.5). Indeed, $\mathrm{APE}_{t}$ and $\Theta$ are reasonably correlated in practice (correlation of 0.80 for 17 runs).

Another step in the argument is to claim that EKE can be related to its dissipation. If the flow field were barotropic (so that bottom stress is proportional to depth averaged or interior velocity) then EKE dissipation would be proportional to $r \mathrm{EKE} / H$. However, the eddy velocities are, for most $r$ values, surface intensified (Fig. 8) so that this would be an overestimate. A correction in terms of the Ekman number can be made so that

$$
\langle\Theta\rangle=r \gamma \mathrm{EKE} / H,
$$

where (empirically)

$$
\gamma=1 /(1+80 \mu) .
$$

This spatially and temporally averaged dissipation rate [(16)] agrees with the calculated dissipation fairly well (correlation $=0.88$ ).

Up to this point, the argument treats consistency relations among model outputs. It is particularly desirable to have an estimate of $\mathrm{APE}_{t}$, hence EKE, based on the original external parameters of the problem. This requires making an analytical estimate of the rate of APE input. If the ocean is quiescent, it is straightforward to use ( $8 b)$ to estimate the rate of change of potential energy (per unit mass) for an ocean with vertical isopycnals as simply

$$
\left\langle\mathrm{PE}_{0 t}\right\rangle=g \beta Q /\left(2 \rho_{0} C_{p}\right) .
$$

However, it is not $\mathrm{PE}_{t}$ but the rate of increase of APE that is of interest. Knowing this requires sorting the density field that led to (17) so that the isopycnals are all flat.

Creating this sorted density field, in general, requires a numerical computation, but the simple geometry presently in use allows an approximation as follows: First, note that the densest unsorted water in the control volume will be at the coast (in the shallowest water), that is,

$$
\left\langle\rho_{C t}\right\rangle=-\beta Q /\left(C_{p} h_{0}\right) .
$$

This water, on sorting, finds its way to the deepest (most offshore) point in the control volume at depth $h(W)=$ $h_{0}+\alpha_{1} W$. The lightest unsorted water is that at the offshore edge of the control region $x=W$ :

$$
\left\langle\rho_{W t}\right\rangle=-\beta Q /\left[C_{p}\left(h_{0}+\alpha_{1} W\right)\right] .
$$

Upon sorting, this water winds up at the surface. An estimate of the sorted density field is then

$$
\begin{aligned}
\left\langle\rho_{z t}^{*}\right\rangle= & -\left(\beta Q / C_{p}\right)\left[\left(h_{0}+\alpha_{1} W\right)^{-1}-h_{0}^{-1}\right]\left(h_{0}+\alpha_{1} W\right)^{-1} \\
& \times\left[1-0.27\left(\alpha_{1} W / H\right)^{2}\right],
\end{aligned}
$$

where the last term, which is proportional to $\left(\alpha_{1} W / H\right)^{2}$, is an approximate geometrical correction to account for the sloping bottom; the sorted $\rho_{z}$ is not actually constant in the vertical unless the bottom is flat.

Using the density estimate [(20)], it is straightforward to estimate the rate of change of PE after sorting:

$$
\begin{aligned}
\left\langle\mathrm{PE}_{S t}\right\rangle= & \Gamma\left[\left(h(0)^{3}-h(W)^{3}\right)\left\langle\rho_{W t}\right\rangle\right. \\
& \left.+1 / 2\left(h(W)^{4}-h(0)^{4}\right)\left\langle\rho_{z t}^{*}\right\rangle\right],
\end{aligned}
$$

where

$$
\Gamma=g\left(6 \rho_{0} \alpha_{1} W H\right)^{-1} .
$$

Finally, the rate of change of APE is the difference of (17) and (21a):

$$
\left\langle\mathrm{APE}_{t}\right\rangle=\left\langle\mathrm{PE}_{0 t}\right\rangle-\left\langle\mathrm{PE}_{S t}\right\rangle .
$$

This form provides a good estimate to the actual maximum rate of APE increase (correlation of 0.98 for 18 runs). [Without the 0.27 geometric correction in (20), the correlation is 0.53 .]

Given an estimate for $\mathrm{APE}_{t}$, an expression for $\langle E K E\rangle$ is obtained by balancing EKE dissipation and APE creation as

$$
\begin{aligned}
\langle\mathrm{EKE}\rangle & =\eta_{1} H \psi(\mu)\left\langle\mathrm{APE}_{t}\right\rangle / r \quad \text { and } \\
& =\eta_{1}\left\langle\mathrm{APE}_{t}\right\rangle\left[1+\eta_{2} /\left(1+\eta_{3} \mu\right)\right] / f,
\end{aligned}
$$


where $\psi$ is yet another empirical function that accounts for the vertical structure of the eddy energy

$$
\psi=\mu\left[1+\eta_{2} /\left(1+\eta_{3} \mu\right)\right] .
$$

Using the $\tau_{A}=0$ runs to optimize the coefficients leads to $\left(\eta_{1}, \eta_{2}, \eta_{3}\right)=(6.7,20,30)$ and a correlation of 0.95 and rms misfit of $2.8 \times 10^{-3} \mathrm{~m}^{2} \mathrm{~s}^{-2}$. Note that (23b) is consistent with Fig. 8 in that the result is largely independent of $\mu$ (hence $r$ ) as $\mu$ becomes large. Expressions (23) imply a rather complicated dependence of EKE on $f$ and especially on $\alpha_{1}$, consistent with the above finding (section 3a) that the dependence on these parameters was not immediately obvious. In a sense, expressions (23) are a complement to Pringle (2001) in that they now add an expression for eddy energy based on $a b$ initio parameters.

Although expressions (23) are a good fit for $\langle$ EKE $\rangle$ when $\tau_{A}=0$, a similarly successful expression could not be found in the cases where alongshore winds are applied. These cases are inherently more complex because of the importance of energy exchanges with MKE as well as that due to baroclinic instability. Applying correction (10) to (23) for $\tau_{A} \neq 0$ yields only mediocre EKE estimates. Another approach is to assume undisturbed isopycnals $[(8 \mathrm{c})]$ and estimate the wind-driven correction to potential energy (hence $\left\langle\mathrm{APE}_{t}\right\rangle$ ). While this approach has some skill (e.g., it improves the correlation for EKE prediction from 0.68 to 0.78 for $\tau_{A}<0$ ), the improvement is still not impressive. The difficulty in this case is evidently because (8c) is a poor estimate of $\rho_{x t}$ once the eddy field is fully developed.

\section{Discussion}

The primary effect of alongshore winds in the presence of surface shelf cooling is that downwellingfavorable winds decrease eddy kinetic energy. For the various runs presented here (all of which involve strong cooling in the sense that convective cooling and homogenization reach the bottom before baroclinic instability dominates); however, the system is always baroclinically unstable and thus the eddy field is never completely suppressed. Whitehead (1981) found in the laboratory that downwelling could completely suppress instabilities, but it is not obvious how well this result might apply in a more oceanic context. For relatively large wind stress amplitude (as measured by $|\Omega|$ ), the system behaves more nearly like an inner shelf in that mean alongshore flows are relatively suppressed, and cross-shelf heat transport due to the mean flow becomes much weaker than the eddy transport. However, because of vertical mixing, strong winds do not eliminate the importance of the eddy field.

Eddy length scale is fairly well characterized by the topographic Rhines scale, which in turn implies a tendency for the eddy scale to increase with EKE, hence cooling. The eddy field always carries heat toward the coast in partial compensation for the ocean's heat loss. Because the model eddy field grows more energetic with stronger cooling, stratification on the shelf, perhaps unintuitively, is expected to grow stronger as the model cooling increases. In a more realistic ocean, where salinity plays an important role in stratification, it is not obvious that this result will carry over. However, observations over the eddy-rich shelf north of Australia, where evaporation leads to a net buoyancy loss to the atmosphere, do show consistent mean density stratification (Shearman and Brink 2010). Although the observations are not sufficiently complete to show a correlation of buoyancy loss to stratification or EKE, the observations are qualitatively consistent with the present results in terms of the importance of an eddy buoyancy flux and overall hydrographic structure. Caution is required, though, because Spall (2005) shows that regional-scale alongshore heat transport, which is absent from this cyclic model, can substantially affect net cross-shelf eddy heat fluxes and thus potentially affect stratification.

One particularly interesting aspect of the eddy field in this problem is that for larger values of the bottom frictional parameter ( $\mu$ greater than around 0.1$)$, the eddy strength and structure are fairly independent of the strength of the friction. This occurs because the eddies adjust, evidently through stratified spindown, so that near-bottom velocities are relatively small. Yet, consistently, eddy energy dissipation at the bottom remains of lowest-order importance. While this sort of adjustment is not unanticipated (e.g., Allen 1984; Arbic and Flierl 2004; Brink 2016), it does have the rather unintuitive consequence of eddy energy levels often being almost independent of bottom friction.

The present modeling results combine with previous modeling studies of stratified conditions (Barth 1994; Durski and Allen 2005; Brink and Seo 2016), gravitationally destabilized systems (e.g., Pringle 2001; Spall 2013), and shelf frontal systems (Brink 2013) to suggest that continental shelf waters are likely to be the site of eddies under most conditions. These eddies would be relatively small $(5-20 \mathrm{~km})$, modestly energetic (swirl velocities of a few centimeters per second), yet present under a very wide range of circumstances: with both surface warming and cooling, with winds or without, and with fronts or without. While such eddies might be a major portion of the subinertial cross-shelf velocity variability, they would be a secondary signal compared to alongshore currents or sea level. Such a ubiquitous 
eddy field would appear to rationalize the observed finding (e.g., Kundu and Allen 1976) that alongshore currents typically have alongshore correlation scales an order of magnitude (or more) greater than do cross-shelf currents. That direct observations of a shelf eddy field are rare is presumably a reflection both of alongshore currents (which have relatively large scales) being energetically dominant and of most observational shelf programs concentrating on scales of $10 \mathrm{~km}$ or greater.

Acknowledgments. Thoughtful comments from Steve Lentz, Jamie Pringle, Roger Samelson, Andrew Stewart, and two anonymous reviewers are greatly appreciated. This research was supported by the National Science Foundation Physical Oceanography Program through Grant OCE-1433953.

\section{REFERENCES}

Allen, J. S., 1984: A simple model for stratified shelf flow fields with bottom friction. J. Phys. Oceanogr., 14, 1200-1214, doi:10.1175/1520-0485(1984)014<1200:ASMFSS > 2.0.CO;2.

Arbic, B. K., and G. R. Flierl, 2004: Baroclinically unstable geostrophic turbulence in the limits of strong and weak bottom Ekman friction: Application to midocean eddies. J. Phys. Oceanogr., 34, 2257-2273, doi:10.1175/1520-0485(2004)034<2257: BUGTIT $>2.0 . \mathrm{CO} ; 2$.

Barth, J. A., 1994: Short-wavelength instabilities on coastal jets and fronts. J. Geophys. Res., 99, 16 095-16115, doi:10.1029/94JC01270.

Brink, K. H., 2013: Instability of a tidal mixing front in the presence of realistic tides and mixing. J. Mar. Res., 71, 227-252, doi:10.1357/002224013807719473.

— 2016: Continental shelf baroclinic instability. Part I: Relaxation from upwelling or downwelling. J. Phys. Oceanogr., 46, 551-568, doi:10.1175/JPO-D-15-0047.1.

— , and H. Seo, 2016: Continental shelf baroclinic instability. Part II: Oscillating wind forcing. J. Phys. Oceanogr., 46, 569-582, doi:10.1175/JPO-D-15-0048.1.

Chapman, D. C., and G. Gawarkiewicz, 1997: Shallow convection and buoyancy equilibration in an idealized coastal polynya. J. Phys. Oceanogr., 27, 555-566, doi:10.1175/ 1520-0485(1997)027<0555:SCABEI >2.0.CO;2.

Durski, S. M., and J. S. Allen, 2005: Finite-amplitude evolution of instabilities associated with the coastal upwelling front. J. Phys. Oceanogr., 35, 1606-1628, doi:10.1175/JPO2762.1.
Haidvogel, D. B., H. G. Arango, K. Hedstrom, A. Beckmann, P. Malanotte-Rizzoli, and A. F. Shchepetkin, 2000: Model evaluation experiments in the North Atlantic basin: Simulations in nonlinear terrain-following coordinates. Dyn. Atmos. Oceans, 32, 239-281, doi:10.1016/S0377-0265(00)00049-X.

Holton, J. R., 1965a: The influence of viscous boundary layers on transient motions in a stratified rotating fluid: Part I. J. Atmos. Sci., 22, 402-411, doi:10.1175/1520-0469(1965)022<0402: TIOVBL $>2.0 . \mathrm{CO} ; 2$.

— 1965b: The influence of viscous boundary layers on transient motions in a stratified rotating fluid: Part II. J. Atmos. Sci., 22, 535540, doi:10.1175/1520-0469(1965)022<0535:TIOVBL>2.0.CO;2.

Kundu, P. K., and J. S. Allen, 1976: Some three-dimensional characteristics of low-frequency current fluctuations near the Oregon coast. J. Phys. Oceanogr., 6, 181-199, doi:10.1175/ 1520-0485(1976)006<0181:STDCOL>2.0.CO;2.

Lentz, S. J., and M. R. Fewings, 2012: The wind-and wave-driven inner-shelf circulation. Annu. Rev. Mar. Sci., 4, 317-343, doi:10.1146/annurev-marine-120709-142745.

Pringle, J. M., 2001: Cross-shelf eddy heat transport in a wind-free coastal ocean undergoing winter time cooling. J. Geophys. Res., 106, 2589-2604, doi:10.1029/2000JC900148.

Shearman, R. K., and K. H. Brink, 2010: Evaporative dense water formation and cross-shelf exchange over the northwest Australian inner shelf. J. Geophys. Res., 115, C06027, doi:10.1029/ 2009JC005931.

Spall, M. A., 2005: Buoyancy-forced circulations in shallow marginal seas. J. Mar. Res., 63, 729-775, doi:10.1357/ 0022240054663204.

- 2013: Dense water formation around islands. J. Geophys. Res. Oceans, 118, 2507-2519, doi:10.1002/jgrc.20185.

_ , and D. C. Chapman, 1998: On the efficiency of baroclinic eddy heat transport across narrow fronts. J. Phys. Oceanogr., 28, 2275-2287, doi:10.1175/1520-0485(1998)028<2275: OTEOBE $>2.0 . \mathrm{CO} ; 2$.

Stewart, A. L., and A. F. Thompson, 2015: Eddy-mediated transport of warm Circumpolar Deep Water across the Antarctic shelf break. Geophys. Res. Lett., 42, 432-440, doi:10.1002/ 2014 GL062281.

Whitehead, J. A., 1981: Laboratory models of circulation in shallow seas. Philos. Trans. Roy. Soc. London, A302, 583-595, doi:10.1098/rsta.1981.0184.

Wijesekera, H. W., J. S. Allen, and P. Newberger, 2003: A modeling study of turbulent mixing over the continental shelf: Comparison of turbulent closure schemes. J. Geophys. Res., $\mathbf{1 0 8}$ 3103, doi:10.1029/2001JC001234.

Winters, K. R., P. N. Lombard, J. J. Riley, and E. A. D'Asaro, 1995: Available potential energy and mixing in density-stratified fluids. J. Fluid Mech., 289, 115-128, doi:10.1017/S002211209500125X. 